\title{
Robótica Pedagógica Livre e Educação a Distância: uma Experiência Formativa
}

\section{Educational Robotics Free and Distance Education: an Experience Training}

\author{
LORENA BÁRBARA DA ROCHA RIBEIRO \\ Universidade do Estado da Bahia - UNEB \\ MARY VALDA SOUZA SALES \\ Universidade do Estado da Bahia - UNEB \\ TARSIS DE CARVALHO SANTOS \\ Universidade do Estado da Bahia - UNEB
}

\begin{abstract}
RESUMO: As transformações ocorridas no mundo, advindas do avanço das Tecnologias de Informação e Comunicação - TIC tiveram reflexos na educação, demandando do professor um novo perfil para sua prática e, consequentemente, uma formação que abarque a fluidez e dinâmica existente nessas tecnologias. Assim, cabe ao professor ressignificar sua prática, buscando alternativas criativas que possibilitem aprendizagens prazerosas e contextualizadas. Nesse cenário, este trabalho se propõe apresentar a Robótica Pedagógica Livre (RPL), em um viés articulador entre tecnologia-prática pedagógica, através de uma experiência formativa de utilização das TIC com a RPL, a partir de um curso a distância. Como metodologia fora adotada a pesquisa participante, considerando que as etapas da formação foram construídas conjuntamente com os sujeitos e trabalhadas no ambiente virtual de aprendizagem. Assim, a RPL pode ser considerada uma proposta de redimensionamento da tecnologia, capaz de potencializar o fazer pedagógico.
\end{abstract}

Palavras-chave: Robótica Pedagógica Livre. Educação a Distância. Formação.

ABSTRACT: The changes occurring in the world, resulting from the advancement of Information and Communication Technologies - ICT, had consequences for education demanding teacher a new profile for his practice and, consequently, a formation that encompasses the fluidity and dynamics existing in these Technologies. So, the teacher reframes his practice, looking for creative alternatives that enable pleasant and contextualized learning. In this case, this study aims to present the Free Educational Robotics in an articulator bias between educational technology and practice through a formative experience that combines the use of ICT with Free Educational Robotics, from a distance learning course. The methodology adopted was action research, considering that the stages of formation were built in conjunction with the subjects and worked in virtual learning environment. So, the Free Educational Robotics can be considered a proposed resizing technology, able to potentiate teaching.

Keywords: Free Educational Robotics. Distance Education. Formation. 
RIBEIRO, Lorena Bárbara da Rocha; SALES, Mary Valda Souza; SANTOS, Tarsis de Carvalho. Robótica Pedagógica Livre e Educação a Distância: uma Experiência Formativa. Informática na Educação: teoria \& prática, Porto Alegre, v. 19, n. 3, p. 192-200, set./dez. 2016.

\section{Introdução}

O processo educativo cada vez mais exige dos educadores alternativas atrativas, criativas para o exercício da prática pedagógica, capazes de promover aprendizagens prazerosas e contextualizadas. Tamanha exigência advém das "transformações" ocorridas no cenário mundial, a partir do avanço das tecnologias digitais, as quais demandam do professor um novo perfil de atuação, capaz de amenizar as urgências formativas da escola atual, a partir de uma caminhada harmoniosa com o uso das potencialidades das Tecnologias de Informação e Comunicação (TIC), adotando "[...] instrumentos às novas práticas de ensino, como meio de articulação, construção e difusão do conhecimento" (SANTOS et al. 2013, p.02) no contexto da escola.

Nesse sentido, este trabalho, no contexto de uma experiência da educação a distância (EAD) discute possibilidades formativas da Robótica Pedagógica Livre e descreve o processo de articulação dessa com as TIC, através de um curso a distância.

Para tanto, dialogamos com autores que pesquisam a temática tais como César (2009), Sales e Nonato (2007), Silva (2008), Hetkowski e Alves (2012), Demo (2009). Como metodologia foi adotada a pesquisa participante, considerando que esta "[...] supõe o contato direto e prolongado do pesquisador com o ambiente e a situação que está sendo investigada" (LÜDKE e ANDRÉ, 1986 p.11), e que é abordado neste trabalho os relatos desse contato, além do detalhamento das etapas da formação que compuseram o curso e que foram sendo construídas conjuntamente com os sujeitos e trabalhadas detalhadamente no ambiente virtual de aprendizagem (AVA) e nas oficinas de formação tecnológica.

Desse modo, apresentamos aqui esse detalhamento da experiência vivenciada no contexto da EAD com a RPL.

\section{Contextualizando o Cenário}

O caráter novo da Robótica Pedagógica Livre (RPL) se sustenta em uma proposta de trabalho baseada na utilização de sucata eletrônica (lixo eletrônico) e Software Livre para (re)construção de artefatos robóticos (CÉSAR, 2009) que são utilizados como recurso didático e pedagógico no processo formativo de maneira geral. Por isso, essa proposta se desenvolve na contramão da robótica convencional (LEGO) que possui estudos sobre experiências de articulação com os processos educativos em espaços formais de educação. A RPL se apresenta aqui, como alternativa inovadora dentro do contexto formativo dos espaços educativos.

Considerando seu foco formativo, fora proposto em 2009 um curso de extensão denominado Robótica Pedagógica Livre 40, ofertado pelo Departamento de Educação - Campus I, da Universidade do Estado da Bahia - UNEB, e coordenado por dois Professores - um da própria universidade e outro de uma instituição parceira-, que objetivou a análise e reflexão sobre as

40 O curso teve início no segundo semestre de 2009, com término de suas ações (englobando as 3 etapas previstas) em 2010 
TIC na educação, especificamente, nos espaços educativos de atuação do Pedagogo com crianças, isto é, Educação Infantil e Ensino Fundamental I41.

Com caráter interdisciplinar, o curso de extensão foi configurado como um espaço de aprendizagem que através de temáticas expostas para debate como: sustentabilidade, inovação, meio ambiente, lixo eletrônico, reciclagem, se constituiu num espaço de trocas e de aprendizagens, o qual contribuiu para o processo de formação dos estudantes envolvidos (MAGRIS NICOLAU; RIBEIRO, 2011), na perspectiva do ensino e da aprendizagem.

Iniciado com 26 participantes e dividido em 3 etapas, o curso tinha o objetivo efetivo de propor possibilidades diversas para criação de recursos didáticos com a RPL que servissem de auxílio na superação de dificuldades pedagógicas no contexto formativo o curso foi desenvolvido no espaço da universidade.

A primeira etapa consistia de elementos:

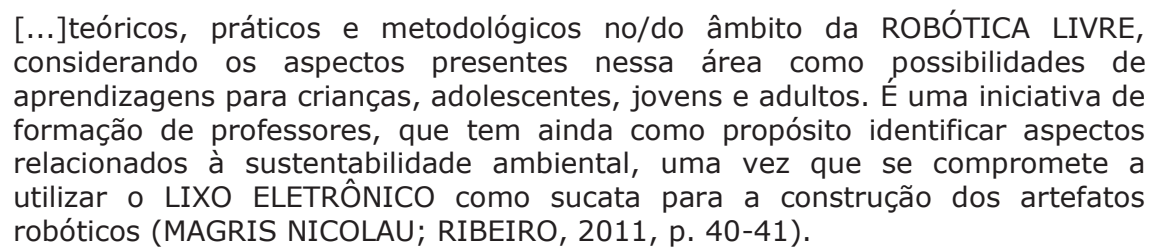

A dinâmica dos encontros da primeira etapa do curso era sempre diversificada e rica, do ponto de vista formativo. $\mathrm{O}$ fato de ter a presença de profissionais e estudantes universitários de diferentes áreas do conhecimento, não só da área de educação, como também estudantes de Engenharia Elétrica, Eletromecânica, Mecatrônica, Design, tornou esses encontros um espaço de troca de conhecimento e saberes dos mais variados conceitos educacionais.

Ao término da primeira etapa, alguns cursistas relataram sobre a experiência vivenciada,

Descobri realmente o que significa robótica, não somente na teoria, mas também na prática que foi a melhor parte. É fascinante esse novo conhecimento, tanto que estou interessada em aprofundar os meus conhecimentos sobre o assunto, através de cursos, que com certeza farei (CURSISTA A, 2010).

Superou as minhas expectativas, pois é uma área muito interessante, e aprendi que temos a capacidade de criar coisas novas e interessantes, para poder estar abordando em sala de aula, com meios (materiais) que estão presentes no nosso dia-a-dia (CURSISTA B, 2010).

Já a segunda etapa, consistiu no planejamento 42 da etapa de multiplicação do curso (terceira etapa); onde se pode aplicar o que fora apresentado e apreendido no decorrer do curso presencial, por meio de oficinas temáticas ofertadas tanto para turmas de educação infantil, ensino fundamental I quanto para turmas do curso Pedagogia / UNEB e de outras instituições.

41 Objetivo constante no projeto e da produção de material de divulgação do curso.

42 Etapa de planejamento feita a distância, de maneira colaborativa, utilizando o ambiente virtual de aprendizagem Moodle. 
Por se tratar de uma etapa onde a interação entre os participantes era importante, por permitir a troca de experiências, saberes e, até mesmo, inseguranças o planejamento acabou tendo como cerne das discussões inquietações sobre ser ou não capaz de realizar a multiplicação do curso. A respeito desses questionamentos, foi possível perceber que

\begin{abstract}
À medida que todos os participantes expressavam as suas inseguranças, dúvidas, angústias e medos, em meio a essas discussões, trazíamos à tona também conhecimentos e saberes sobre interdisciplinaridade, transdisciplinaridades, multidisciplinaridade, teorias da aprendizagem, processos cognitivos, interfaces, fazendo-nos perceber que o "pedagógico" não estava tão distante quanto pensávamos, e que tínhamos sim, condições de nos tornamos multiplicadores (MAGRIS NICOLAU; RIBEIRO, 2011 p. 41).
\end{abstract}

Contudo, ainda que essas incertezas permeassem as discussões entre os cursistas, a relevância da etapa de planejamento é reforçada quando consideramos como elemento basilar a aprendizagem proporcionada em ambiente diferenciado, que permite aos sujeitos envolvidos ampliar seus conhecimentos por meio de um trabalho multidisciplinar, mediado pelas TIC.

Além disso, vale salientar que alternativas como essa do curso de Robótica Pedagógica Livre oferecem à formação de professores possibilidades de aquisição de informações que podem contribuir para o desenvolvimento de habilidades e competências para o planejamento, a implementação e a atuação em projetos educativos em diferentes espaços de aprendizagem, nos diversos contextos educativos e formativos (MAGRIS NICOLAU; RIBEIRO, 2011).

\title{
3 A etapa de planejamento: os protagonistas da ação extensionista e o processo formativo
}

O acompanhamento do processo formativo na perspectiva teórica, foi desenvolvido através de possibilidades comunicacionais e midiáticas promovidas pela modalidade de Educação a Distância (EaD), que nessa experiência, foi elemento de destaque na ação de extensão, por estar diretamente ligada ao uso efetivo do conjunto de ferramentas que é derivado das chamadas Tecnologias da Informação e Comunicação (TIC).

Destacamos que nesse contexto, a EAD permite a ampliação dos processos de discussão sobre a temática e, consequentemente, da formação, pois com a participação de profissionais de diversas áreas do conhecimento, com competência legitimada em suas práticas em outros espaços de aprendizagem, dentro e fora do país, que em função das distâncias reais-concretas, (com)partilharam suas experiências graças as TIC no utilizadas na proposta EAD.

Assim, a formação é compreendida como "um processo contínuo e permanente de desenvolvimento, no qual o professor aprende a aprender, se identifica como profissional da educação e cidadão inserido numa sociedade multicultural, plural e em permanente transformação" (SALES; NONATO, 2007). Nessa perspectiva, considera-se a etapa de planejamento da multiplicação como a mais inquietante dentro de todo processo de desenvolvimento do curso, do processo formativo em si, visto que as pessoas precisavam se sentir na condição de ensinante e aprendente para que a mesma obtivesse sucesso. 
O fato de utilizar o ambiente virtual de aprendizagem (AVA) como extensão da sala de aula presencial, no sentido de que ali também se constituía em um espaço de interações, de construções coletivas, de questionamentos e, consequentemente, de aprendizagens, é que pensar a EAD como possibilidade de efetivar a educação a partir do advento das TIC, contribuiu efetivamente para o desenvolvimento de uma prática de formação voltada para as práticas sociais com mais discussões, diálogos, trocas de experiências e aprendizagens compartilhadas, qualificando a proposta de multiplicação da experiência formativa com a RPL.

Contudo, vale ressaltar que mesmo considerando o Ambiente Virtual de Aprendizagem (AVA) extensão da sala de aula presencial, a EAD online demanda do docente metodologias que sejam realizadas em consonância com a dinâmica de comunicação da cibercultura, para que não tenhamos práticas transpostas de repetição equivocada de métodos tradicionais, os quais não extrapolaram o espaço físico presencial. Nessa direção, Silva (2008 p. 69) alerta que:

Na modalidade online professor permanece ainda tratando os aprendizes como recipientes de informação e não como agentes de colaboração, de compartilhamento e de co-criação, hábitos e comportamentos que se desenvolvem com a cibercultura.

Nesse contexto, se faz necessário (re)pensar sobre as metodologias docentes que estão sendo utilizadas na educação a distância online, para que se busque sempre promover nos AVA, um espaço interativo, participativo que possibilitem a formação de discentes autônomos e autores do seu processo formativo.

Pensando nessas metodologias, Silva (2008) sugere que o docente tenha uma prática equivalente ao "movimento" do hipertexto digital, ou seja, não linear, multidirecional e aberta, com conexões múltiplas, permitindo assim maior interatividade; onde os professores se percebam não como meros transmissores de informação, mas como sujeitos multifacetados, capazes de provocar inquietações, desequilíbrios/equilíbrios, aprendizagens significativas. Silva (2008) sugere 5 objetivos a serem desenvolvidos para que o docente construa uma mediação interativa. São eles:

1. Propiciar oportunidade de múltiplas experimentações, múltiplas expressões;

2. Disponibilizar uma montagem de conexões em rede que permita múltiplas ocorrências;

3. Provocar situações de inquietações criadora;

4. Arquitetar colaborativamente percursos hipertextuais;

5. Mobilizar a experiência do conhecimento (p. 77)

Portanto, o professor precisa, para viver essa experiência formativa potencialmente, se despir de velhos hábitos, dando espaço a uma prática colaborativa, interativa, sendo mobilizador de inquietações, de saberes; ao aluno, por sua vez, compete sair de cena o "receptor" de conhecimento/informações, sujeito passivo, para dar lugar ao autor/ator de seu processo formativo, ativo na prática de formação. 
E foi nessa perspectiva, de ser protagonista no percurso formativo, que transcorreram as atividades de planejamento da etapa de multiplicação do curso de Robótica Pedagógica Livre. Não somente o protagonismo discente, como também foram oportunizadas múltiplas experimentações com o intuito de promover o desenvolvimento da autonomia e criatividade, com as diversas mídias no contexto das práticas da formação promovidas na modalidade de EaD e pela interrelação da proposta específica do curso com áreas distintas do conhecimento.

\section{Traçando as linhas finais do planejamento: o empoderamento das TIC a favor da formação}

Dando sequência a caracterização do curso, as etapas propostas durante a fase de planejamento da multiplicação foram cruciais não somente como elementos que auxiliariam na composição das atividades a serem aplicadas, como também para ampliação do conteúdo que fora apreendido durante a fase inicial. Para isso, foram utilizados dentre os recursos ofertados no ambiente virtual de aprendizagem Moodle os fóruns de discussão (sobre RPL; planejamento; sustentabilidade; entre outros); Wiki (para construção colaborativa das fases do planejamento).

Tais recursos foram escolhidos considerando que possuem características peculiares que demarcaram toda a trajetória do curso como a colaboração, interação, além de possibilitar uma fácil comunicação e difusão das aprendizagens elaboradas. Essas especificidades quase que inerentes a um curso a distância, permitiram, juntamente com mediador, que os cursistas se enxergassem como parte do processo formativo, capazes de "[...] desenvolver-se como sujeito autônomo e crítico ao tempo em que constrói o conhecimento objetivo a que se propôs" (SALES e NONATO, 2007, p.2).

Nessa perspectiva de autonomia, sujeito autônomo, crítico, colaborativo, cabe aqui algumas ponderações acerca do papel das TIC como elemento mediador da formação (trajetória formativa), visto que estas

[...] potencializam a autonomia, emancipação e a criticidade, por meio do ato educativo, permitindo aos sujeitos o direito de escolha, constituindo uma abordagem crítica, subvertendo as práticas instituídas e reinscrevendo um modo de ser e pensar fundados na diferença, na solidariedade, na colaboração frente aos discursos hegemônicos alienantes (SANTOS et al, 2014, p. 681).

As características elencadas acima destacam o perfil transformativo e criativo potencializado pelas TIC; capaz de mobilizar a reflexão acerca do cenário educacional, e assim, possibilitar formas outras de ensinar e aprender, que consigam romper com a linearidade que permeia 0 processo educacional mais clássico no modelo de sala de aula física, tradicional.

A Educação a Distância mediada pelas TIC retrata bem esse possível rompimento, pois com o suporte digital inaugura uma nova característica desenvolvida nas relações, que é a interatividade, considerando que esta "[...] não se caracteriza, apenas, entre a conexão entre 
pessoas, mas sim na conexão simultânea entre pessoas, informações e conhecimentos" (SANTOS et al, 2014, p. 684).

Nessa perspectiva, não se pode negar que as TIC permitem além do amplo acesso ao conhecimento, "infinitas maneiras de aprender bem" (DEMO, 2009, p. 53), oportunizadas por atividades que articulam e fortalecem um imbricamento autoria e autonomia, considerando que estes são elementos basilares do processo de aprendizagem mediado pelas TIC e, na experiências descrita a articulação indicada foi a mola propulsora para o sucesso do curso, uma vez que a formação no AVA sustentou o desenvolvimento das oficinas presenciais, assim como se configurou como espaço de avaliação permanente das práticas de formação com a RPL.

\section{Conclusão}

Pensar alternativas de/para formação continuada se faz necessário de maneira que estas permitam a aquisição de informações que possibilitem o desenvolvimento de habilidades e competências para o planejamento, a implementação e a atuação em espaços de aprendizagem nos diversos contextos de educação.

Partido desse pressuposto, pode-se considerar que esse curso de maneira muito articulada, oportunizou experiências formativas envolvendo a tecnologia a partir de duas perspectivas. A primeira, relaciona-se a Robótica Pedagógica Livre e a sua proposta de ressignificação de uma "tecnologia" outrora descartada (lixo eletrônico), mas que agora ganha um novo direcionamento - confecção de artefatos robóticos a partir da sucata eletrônica para inserção/uso como recurso pedagógico, podendo auxiliar no processo de ensino-aprendizagem de crianças com dificuldade de aprendizagem, por exemplo.

Sobre esse aspecto, alguns cursistas, dos 09 que concluíram o curso43, relataram que

Esse novo método de "fazer" robótica nos mostrou o quanto esse universo é ilimitado. Tal, nos oferece a oportunidade de explorar a criatividade, pôr em prática nossos desejos enquanto "programadores" em formação, além de ser acessível para aqueles que muitas vezes não tem condições de trabalhar com a tecnologia de ponta (CURSISTA C, 2010).

A experiência vivenciada no curso de robótica pedagógica livre foi maravilhosa. Foi possível o despertar do nosso lado criativo, como também oportunizando a inclusão digital e nas áreas de eletromecânica. O que gera novos conhecimentos, novas oportunidades, novas experiências, tudo isso de forma ecológica sem agredir a natureza, além de tudo proporcionando inovação. Nos levando um olhar aguçado sobre questões referentes à tecnologia (CURSISTA D, 2010).

A segunda perspectiva diz respeito a Educação a Distância; ao processo formativo mediado pelas Tecnologias da Informação e Comunicação, as quais possibilitam o exercício efetivo da autonomia, onde o sujeito pode, ao mesmo tempo, exercer sua condição de ator (protagonista principal do seu processo formativo) e autor (onde constrói os próprios caminhos a serem percorridos afim de se chegar a excelência) da sua formação.

43 Os 17 participantes que desistiram do curso o fizeram por livre escolha. 41,17\% dos desistentes alegaram falta de tempo, 29,41\% alegaram que estavam cursando muitas disciplinas e não conseguiam conciliar com o curso e $29,41 \%$ dos cursistas desistentes nada justificaram. 
Essas duas perspectivas oportunizaram a compreensão mais concreta e próxima da tradução de Tecnologia como processo criativo, transformativo a favor da articulação entre educação e tecnologia. Além disso, percebemos que é possível a integração de processos formativos desenvolvidos a partir de suportes diversos, pois na experiência em tela a RPL foi o fundamento "curioso" que estimulou a interação e interatividade na formação na modalidade EAD e a criatividade nas oficinas práticas de trabalho pedagógico com a RPL.

\section{Referências}

CÉSAR, Danilo Rodrigues. Robótica Pedagógica Livre: Uma possibilidade metodológica para o processo de ensino-aprendizagem. Disponível em: http://libertas.pbh.gov.br/ danilo.cesar/robotica_livre/artigos/artigo_epenn_2009.pdf Acesso em: 12 set. 2009.

DEMO, Pedro. Aprendizagens e Novas Tecnologias. Revista Brasileira de Docência, Ensino e Pesquisa em Educação Física - ISSN 2175-8093 - Vol. 1, n. 1, p.53-75, Agosto/2009

HETKOWSKI, T.; ALVES, L. (Orgs.). Tecnologias Digitais e Educação: Novas (re)configurações técnicas, sociais e espaciais. Salvador: Eduneb, 2012.

LIMA JR, Arnaud Soares de. Tecnologias Inteligentes e Educação: Currículo Hipertextual. Rio de Janeiro: Quartet; Juazeiro, BA: FUNDESF, 2005 (Cibercultura e educação; v.2).

LÜDKE, Menga; ANDRÉ, Marli E.D.A. Pesquisa em educação: abordagens qualitativas. São Paulo: EPU, 1986.

MAGRIS NICOLAU, Patrícia; RIBEIRO, Lorena B R. Robótica Pedagógica Livre: Seus "usos" como material didático-pedagógico no processo de formação do(a) professor (a), no contexto escolar da Educação Básica e nos espaços multirreferenciais de aprendizagem na sociedade contemporânea. In.: Revista Espirito Livre: p. 40-44, Nov. 2011.

ROCHA, Carlos Alves. Mediações tecnológicas na educação superior. Vol.5. Curitiba: Ibpex, 2009.

SALES, M. V. S.; NONATO, E. R. S. EAD e material didático: reflexões sobre mediação pedagógica. $13^{\circ}$ Congresso Internacional de Educação a Distância. Curitiba, Paraná, Brasil. Setembro de 2007.

SANTOS, T.C; FERREIRA, M.A.M; RIBEIRO, L.B.R. Era Digital: A Formação do Professor Contemporâneo para uma Práxis Tecnológica. In: III Simpósio Baiano de Licenciaturas - Articulação entre ensino Superior e Educação Básica: A construção de Políticas Públicas de Formação de Professores. Cruz das Almas: 2013.

SANTOS, T. C. ; CORREIA, S. L. C. P. ; ARAUJO, K. S. S. ; FERREIRA, M. A. M. ; RIBEIRO, L. B. R. . Formação de Professores e TIC: Tecendo outras Possibilidades. In: VIII Simpósio Nacional de Educação, 2014, Frederico Westphalen. VIII Simpósio Nacional de Educação, 2014.

SILVA, Marco. Cibercultura e educação: a comunicação na sala de aula presencial e online. Revista FAMECOS. Porto Alegre, $n^{\circ}$ 37, dez. 2008.

Submetido para avaliação em 06 de março de 2016.

Aprovado para publicação em 06 de setembro de 2016. 
Lorena Bárbara da Rocha Ribeiro

Programa de Pós-Graduação em Educação e Contemporaneidade - Universidade do Estado da Bahia, Brasil, lore_barbara@hotmail.com

\section{Mary Valda Souza Sales}

Programa de Pós-Graduação em Educação e Contemporaneidade - Universidade do Estado da Bahia, Brasil, maryssales@gmail.com

Tarsis de Carvalho Santos

Programa de Pós-Graduação em Educação e Contemporaneidade - Universidade do Estado da Bahia, Brasil, ths.carvalho@hotmail.com 